\title{
Analysis of the clinicopathological features and prognostic factors of primary hepatic neuroendocrine tumors
}

\author{
REN-WANG CHEN ${ }^{1 *}$, MENG-JUN QIU ${ }^{2 *}$, YAOBING $\mathrm{CHEN}^{3}$, TAO ZHANG ${ }^{1}$, XIAO-XIAO HE ${ }^{2}$, \\ YING LI ${ }^{4}$, WEN-JIA SUN ${ }^{4}$, TAO XIE ${ }^{4}$, SHENG-LI YANG ${ }^{1}$ and JIAN-LI HU ${ }^{1}$ \\ ${ }^{1}$ Cancer Center, Union Hospital, Tongji Medical College, Huazhong University of Science and Technology, Wuhan, \\ Hubei 430022; ${ }^{2}$ Division of Gastroenterology, Liyuan Hospital, Tongji Medical College, Huazhong University of \\ Science and Technology, Wuhan, Hubei 430077; ${ }^{3}$ Institute of Pathology, Tongji Hospital, Tongji Medical College, \\ Huazhong University of Science and Technology, Wuhan, Hubei 430022; ${ }^{4}$ Department of \\ Radiation Oncology, Hubei Cancer Hospital, Wuhan, Hubei 430070, P.R. China
}

Received October 27, 2017; Accepted March 20, 2018

DOI: $10.3892 / \mathrm{ol} .2018 .8413$

\begin{abstract}
Neuroendocrine tumors (NETs) of the gastrointestinal tract often spread to the liver, while primary hepatic NETs (PHNETs), first described by Edmondson in 1958, are very rare. The majority of existing reports regarding PHNETs have small sample sizes, and the clinicopathological characteristics and prognostic factors are still unclear. The aim of the present study was to analyze the clinicopathological features and explore the prognostic factors of PHNETs. From March 2012 to March 2017, 28 cases of PHNETs were retrospectively evaluated to analyze the clinicopathological features and explore the prognostic factors of PHNETs. The 28 PHNETs patients were males $(n=15)$ and females $(n=13)$ aged between 32 and 76 years (mean=53 years). Among them, 16 patients had clinical symptoms. The remaining 12 patients had no obvious clinical symptoms, only hepatoncus was observed during physical examination. Single-factor analysis
\end{abstract}

Correspondence to: Dr Sheng-Li Yang or Professor Jian-Li Hu, Cancer Center, Union Hospital, Tongji Medical College, Huazhong University of Science and Technology, 1277 JieFang Avenue, Wuhan, Hubei 430022, P.R. China

E-mail: yangshengli2014@yahoo.com

E-mail: j15199@126.com

"Contributed equally

Abbreviations: PHNETs, primary hepatic neuroendocrine tumors; CA125, carbohydrate antigen 125; ALT, alanine aminotransferase; AST, aspartate aminotransferase; HB, hemoglobin; PI, Ki-67 positive index; CT, computed tomography; AFP, $\alpha$-fetoprotein; CEA, carcinoembryonic antigen; CGA, chromogranin A; NEC, neuroendocrine carcinoma; NET, neuroendocrine tumor; HPF, high power field

Key words: liver neuroendocrine tumor, liver neuroendocrine carcinoma, primary, prognosis showed that carbohydrate antigen 125 (CA125), alanine aminotransferase (ALT), aspartate aminotransferase (AST), hemoglobin (HB), Ki-67 positive index (PI), surgical treatment and pathological grading were correlated to PHNET prognosis $(\mathrm{P}<0.05)$; multifactor analysis revealed that Ki-67 PI was associated with the prognosis $(\mathrm{P}<0.05)$. Thus, the prognosis of PHNETs may be effectively predicted using the indexes of CA125, ALT, AST, HB, Ki-67 PI, pathological grading and surgical treatment. Pathological classification of grade 3, high expression of Ki-67 PI, abnormal elevation of CA125, abnormalities of ALT and AST, anemia and lack of radical operation indicated a poor prognosis. High expression of Ki-67 PI was an independent prognostic factor for PHNETs.

\section{Introduction}

Neuroendocrine neoplasms are a group of heterogeneous tumors that originate from peptidergic neurons and neuroendocrine cells (1). With the widespread use of immunohistochemical techniques and electron microscopy in the pathological diagnosis of tumors, neuroendocrine tumors (NETs) have been found not only in endocrine but also in non-endocrine organs, such as the gastrointestinal tract, pancreas, gall bladder and lung. (2). The incidence of NETs in the gastrointestinal tract was reported to be $45 \%$ in the small intestine, $20 \%$ in the rectum, $17 \%$ in the appendix, $11 \%$ in the colon, and $7 \%$ in the stomach (2).

NETs of the gastrointestinal tract often spread to the liver, while primary hepatic NETs (PHNETs), first described by Edmondson in 1958, are very rare (3). Existing reports about PHNETs are mostly of small sample sizes, and the clinicopathological characteristics and prognostic factors of PHNETs are still unclear (4-7). Here, we collected and classified the clinicopathological features of 28 PHNETs patients [9 in Wuhan Union Hospital (Wuhan, China), 15 in Tongji Hospital (Wuhan, China), and 4 in Hubei Cancer Hospital (Wuhan, China)] and discussed whether the related clinicopathological indicators can be used to improve the prognostic analysis of PHNETs. 


\section{Materials and methods}

Ethical approval. Ethical approval was requested and obtained from the Medical Ethics Committee of Tongji Medical College (Wuhan, China). Written informed consent was obtained from all participants.

Clinical data collection. We collected liver tissue specimens by excision or needle biopsy from 32 patients who were diagnosed with PHNETs in Wuhan Union Hospital, Tongji Hospital, and Hubei Cancer Hospital between 2012 and 2017. Among them, 28 patients were of pathological and follow-up data integrity, and thus eligible for histopathological and prognostic analysis. The clinicopathological features of all patients were reviewed and analyzed. Cases were examined by imaging, histopathological and immunohistochemical analysis, and long-term postoperative follow-ups, including ultrasound, enhanced chest computed tomography (CT), and upper and lower gastrointestinal endoscopic examination, were conducted. No primary extrahepatic lesions were found, so all patients were eventually diagnosed with PHNETs. We confirm that we obtained informed consent of all 28 patients.

Observation indexes. Clinical indicators for observation: Tumor size $(\leq 5 />5 \mathrm{~cm})$ and treatment (radical surgery/others). Biochemical indicators: Alpha fetoprotein (AFP; $\leq 400 />400 \mathrm{ug} / \mathrm{l})$, carcinoembryonic antigen (CEA; $\leq 5 / 1 />5 \mathrm{ug} / 1$ ), carbohydrate antigen 125 (CA125; $\leq 35 />35 \mathrm{ug} / \mathrm{ml})$, ALT $(\leq 40 />40 \mathrm{U} / \mathrm{l})$, aspartate aminotransferase $(\mathrm{AST} ; \leq 40 />40 \mathrm{U} / 1)$, albumin $(\leq 35 />35 \mathrm{G} / 1)$, and hemoglobin (HB; $\leq 110 />110 \mathrm{G} / 1)$. Pathological indicators: Tumor grading (G1, G2/G3), Ki-67 PI ( $\leq 20 />20 \%)$, and chromogranin A (CGA; -/+; Fig. 1).

Follow-up results. 28 patients were followed up. Follow-up time ranged from 2 to 50 months (mean, 18.7 months; median survival time, 18.0 months). No tumor recurrence was found in any of the cases who received a liver transplantation until the end of the follow up. One case had no diarrhea after treatment and survived tumor-free for 16 months. Of the 18 dead cases, 15 were neuroendocrine carcinoma (NEC) and 3 were NET G2. One case of NEC died after a follow-up period of two months. The rest of cases were followed up for more than 5 months.

WHO classification (2010) of tumors of the digestive system. NET classification criteria were as follows: NET G1: Mitotic figure $<2 / 10 \mathrm{HPF}$ and/or PI $\leq 2 \%$; NET G2: Mitotic figure (2-20)/10 HPF and/or PI 3-20\%; and NEC/G3: Mitotic figure $>20 / 10 \mathrm{HPF}$ and/or Ki-67 PI >20\% (8).

Statistical analysis. SPSS statistical software (version 18.0) was used for statistical processing. The indexes age, sex, tumor size, tumor grade, AFP, CEA, CA125, ALT, albumin, HB, CGA, surgery received, and Ki-67 PI were compared between NET (G1, G2) and NEC (G3) applying the Mann-Whitney and Pearson chi-square tests. Variance analysis of the effects of the pathologic indexes on the prognosis was performed by the Kaplan-Meier survival curve and the log-rank test; $\mathrm{P}<0.05$ was considered to indicate a statistically significant difference.

\section{Results}

Clinicopathological data. Among the 28 patients, 15 were male and 13 were female, corresponding to a male/female ratio of 1.15:1.0. Patients were aged between 32 and 76 years (mean $=53$ years). Sixteen patients had clinical symptoms, with 15 patients having epigastric discomfort as their first symptom and one having diarrhea. For the rest 12 patients, no obvious clinical symptoms, except hepatoncus, were found during physical examination (Fig. 2). Five patients had a history of hepatitis B. Auxiliary examinations showed that 1 case $(3.5 \%)$ had an elevated serum AFP, information of 2 cases (7.1\%) were not available, and the rest of cases were in the normal range. For CEA, 1 case $(3.5 \%)$ had an elevated serum CEA, information of 2 cases $(7.1 \%)$ were not available, and the rest of cases were in the normal range. For CA199, 4 cases $(14.3 \%)$ had an elevated serum CA199, information of 2 cases (7.1\%) were not available, and the rest of cases were in the normal range. For CA125, 3 cases (10.6\%) had an elevated serum CA125, information of two cases $(7.1 \%)$ were not available, and the rest of the cases were in the normal range. Twenty-two cases were single tumors (78.6\%), and 6 cases were multiple tumors (21.4\%; Table I). All cases $(100 \%, 28 / 28)$ were immunohistochemically positive for synaptophysin. Among these cases were 20 cases $(71.4 \%)$ in the G3 group, and 14 cases $(50 \%)$ received the radical operation.

Classification and related prognostic indicators. The 28 cases of PHNETs were divided into the groups NET G1 (3 cases), NET G2 (5 cases), and NEC G3 (20 cases). For each group, the indexes age, sex, tumor size, tumor grade, AFP, CEA, CA125, ALT, albumin, HB, CGA, as well as surgery received were detected, and correlation analysis was performed applying the Mann-Whitney or Pearson chi-square test (Table II). Then, these clinicopathological features and the prognosis were tested by single factor analysis. The groups NET G1 and NET G2 were combined into one group and compared with the NEC G3 group. The survival curve showed that the survival rate of the NET $(\mathrm{G} 1, \mathrm{G} 2)$ group was higher than that of the NEC (G3) group $(\mathrm{P}<0.05)$. The average survival time was $37.3 \pm 5.3$ months for the NET group and 14.9 \pm 2.5 months for the NEC group. Cases of Ki-67 PI $\leq 20 \%$ were compared with cases of Ki-67 PI $>20 \%$, and the survival curve showed that the group of $\mathrm{Ki}-67 \mathrm{PI} \leq 20 \%$ had a higher total survival rate than the group of $\mathrm{Ki}-67 \mathrm{PI}>20 \%(\mathrm{P}<0.05)$. The average survival time was $36.1 \pm 5.2$ months for the group of $\mathrm{Ki}-67 \mathrm{PI} \leq 20 \%$ and $12.0 \pm 1.7$ months for the group of $\mathrm{Ki}-67 \mathrm{PI}>20 \%$. The cases of ALT $\leq 40 \mathrm{U} / 1$ were compared with the cases of ALT $>40 \mathrm{U} / 1$, and the survival curve showed that the group of ALT $\leq 40 \mathrm{U} / 1$ had a higher total survival rate than the group of ALT $>40 \mathrm{U} / 1$ $(\mathrm{P}<0.05)$. The average survival time was $26.7 \pm 4.2$ months for the group of ALT $\leq 40 \mathrm{U} / 1$ and $12.4 \pm 1.7$ months for the group of ALT $>40 \mathrm{U} / 1$. Cases of AST $\leq 40 \mathrm{U} / 1$ were compared with cases of AST $>40 \mathrm{U} / 1$, and the survival curve showed that the group of $\mathrm{AST} \leq 40 \mathrm{U} / 1$ had a higher total survival rate than the group of AST $>40 \mathrm{U} / 1(\mathrm{P}<0.05)$. The average survival time was $28.7 \pm 5.0$ months for the group of AST $\leq 40 \mathrm{U} / 1$ and $14.4 \pm 2.4$ months for the group of AST $>40$ U/1. Cases of CA125 $\leq 35 \mathrm{ug} / \mathrm{ml}$ were compared with cases of CA125 $>35 \mathrm{ug} / \mathrm{ml}$, and the survival curve showed that the group of 

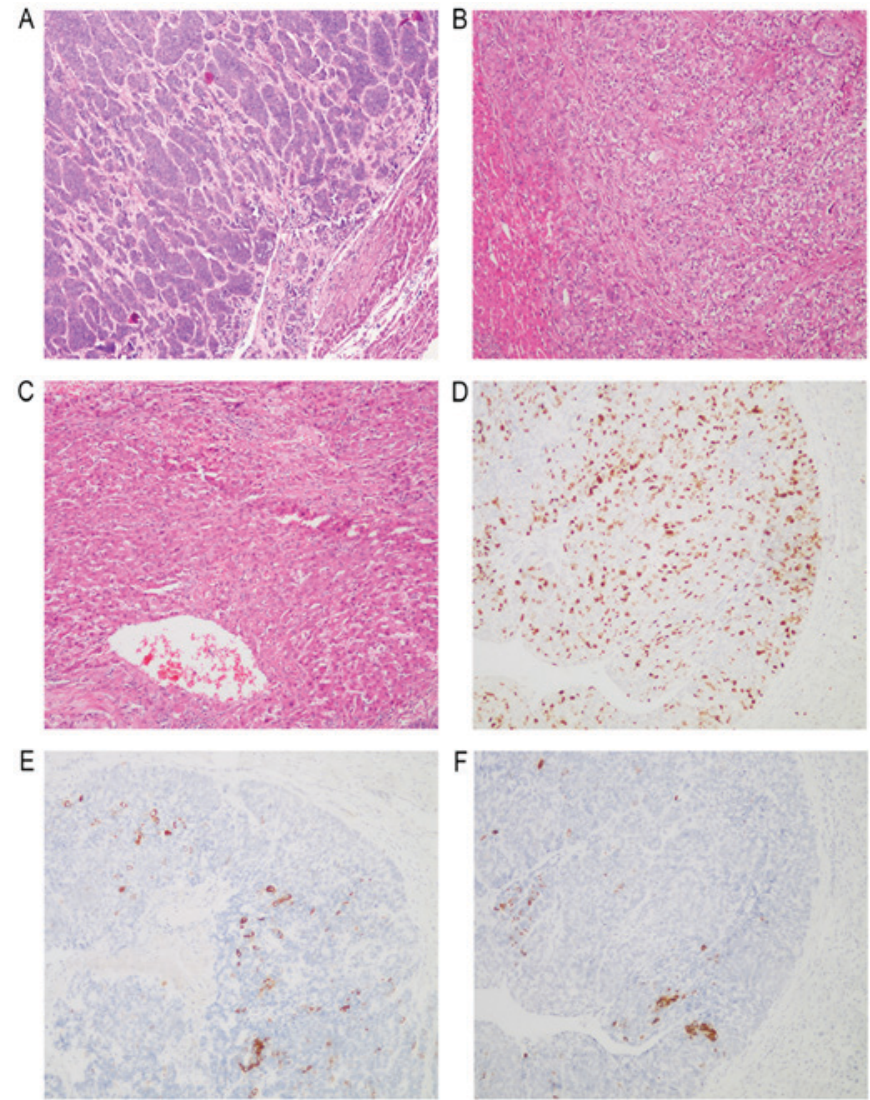

Figure 1. Histological findings in liver tumors. (A) NET G1, histological examination showed that the tumor cells were arranged into trabeculae, gland bubbles or gyrus. The nucleus was centered. Small and round, with relatively uniform size. (B) NET G2, histological examination showed that the tumor cells were arranged in the adenocarcinoma or cerebral gyrus, and the core was larger than NET G1, and moderately atypical. (C) NEC G3, histological examination showed that the tumor cells were arranged in large nests or parenchyma, without organs, and the nuclei were round, elliptical, irregular or spindle, and can be seen in giant cells of the tumor. (D) Immunohistochemistry revealed the tumor cells were positive for $\mathrm{Ki}-67$. (E) Immunohistochemistry revealed the tumor cells were positive for synaptophysin. (F) Immunohistochemistry revealed the tumor cells were positive for chromorgranin A (magnification, x100). NET, neuroendocrine tumor; G1-3, tumor grades 1-3; NEC, neuroendocrine carcinoma.

CA125 $\leq 35 \mathrm{ug} / \mathrm{ml}$ had a higher total survival rate than the group of $\mathrm{CA} 125>35 \mathrm{ug} / \mathrm{ml}(\mathrm{P}<0.05)$. The average survival time was $24.5 \pm 3.8$ months for the group of CA125 $\leq 35 \mathrm{ug} / \mathrm{ml}$ and $8.3 \pm 3.8$ months for the group of CA125 $>35 \mathrm{ug} / \mathrm{ml}$. Cases of $\mathrm{HB} \leq 110 \mathrm{G} / 1$ were compared with cases of $\mathrm{HB}>110 \mathrm{G} / 1$, and the survival curve showed that the group of $\mathrm{HB}>110 \mathrm{G} / 1$ had a higher total survival rate than the group of $\mathrm{HB} \leq 110 \mathrm{G} / 1$ $(\mathrm{P}<0.05)$. The average survival time was $25.5 \pm 3.7$ months for the $\mathrm{HB}>110 \mathrm{G} / 1$ group and $10.5 \pm 2.7$ months for the $\mathrm{HB} \leq 110 \mathrm{G} / 1$ group. Cases who had received a surgical operation were compared with those who had not received any surgical operation, and the survival curve showed that the operated group had a higher total survival rate than the non-operated group $(\mathrm{P}<0.05)$. The average survival time was $31.3 \pm 6.1$ months for the operated group and $15.3 \pm 2.1$ months for the non-operated group. The survival time is not correlated to sex, age $(\leq 50$ or $>50)$, tumor size $(\leq 5$ or $>5 \mathrm{~cm})$, and the immunohistochemical result of CGA (negative or positive; P>0.05; Fig. 3). All clinicopathological features that had a

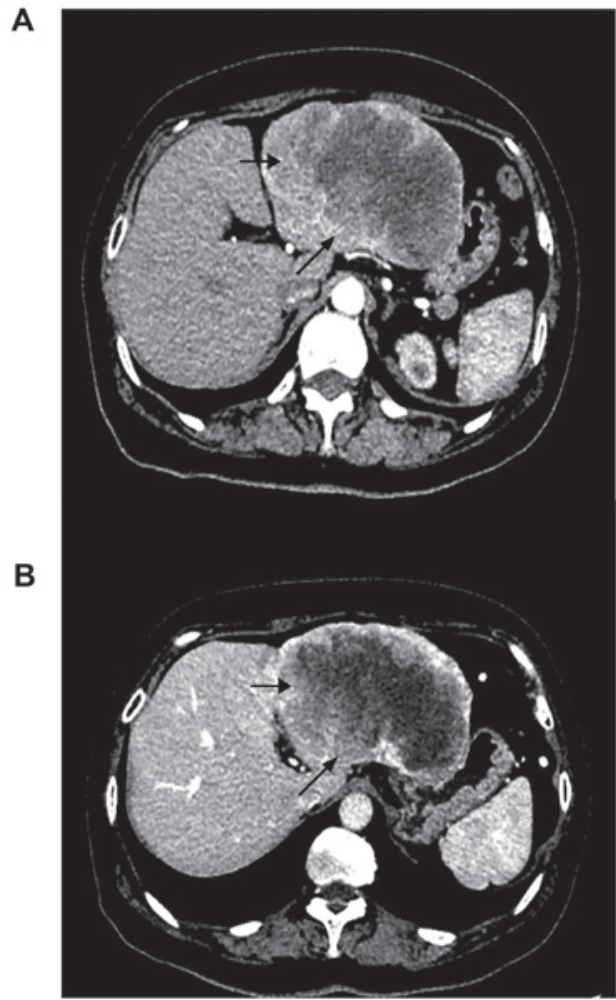

Figure 2. Dynamic liver computed tomography scan revealed a $12 x 6.5 \mathrm{~cm}$ mass in the left lobe of the liver. (A) The arterial phase revealed marked non-uniform enhancement of the tumor and notable necrosis in the center of the mass. (B) The enhanced attenuation of the portal tumor evolved into a low-density shadow. Arrows indicate tumor sites.

positive result in the single-factor analysis were further tested by multiple-factor analysis, revealing that only $\mathrm{Ki}-67 \mathrm{had}$ a correlation with prognosis. To sum up, testing the effects of various clinicopathological indicators on the prognosis showed that tumor group, Ki-67 PI, CA125, ALT, AST, HB, and whether surgery had been received can significantly affect the survival rate of patients, demonstrating that these indicators have important roles in evaluating the severity and prognosis of PHNETs. Especially Ki-67 PI, which can be an independent prognostic factor. The effects of tumor size, AFP, CEA, CGA, and albumin on severity evaluation and prognosis were limited (Table III).

\section{Discussion}

PHNETs accounts for $0.3-4.0 \%$ of the NETs, while reports of PHNETs are mainly of individual cases, so there is very little understanding of the clinicopathological features and the biological behavior of this disease (8-11). Diagnosis of PHNETs depends on three dispensable consecutive stages, the preoperative, intraoperative, and postoperative stage (12). Pathology is the gold standard in NET diagnosis, but it is impossible to distinguish a primary from a metastatic tumor only based on the pathological morphology (11). Therefore, comprehensive and careful intraoperative examinations as well as long-term postoperative follow-ups are essential to detect tiny extrahepatic primary lesions. Follow-up examinations include gastrointestinal endoscopy, abdominal ultrasound, thoracic abdominal CT and MRI. In our study, most of the 
Table I. Main demographic, biochemical and clinical characteristics of the 28 primary hepatic neuroendocrine tumor patients.

\begin{tabular}{llc}
\hline Variable & \multicolumn{1}{c}{ Unit } & Value \\
\hline Age & Years & $53(32-76)$ \\
Sex & Male & $15(53.5 \%)$ \\
Albumin & $\mathrm{g} / \mathrm{l}$ & $39(25-49)$ \\
ALT & $\mathrm{U} / 1$ & $83(11-834)$ \\
AST & $\mathrm{U} / 1$ & $63(16-159)$ \\
PHNET diameter & $\mathrm{cm}$ & $6.5(1.5-18)$ \\
AFP & $\mathrm{ng} / \mathrm{ml}$ & $56(2-1499)$ \\
HB & $\mathrm{g} / \mathrm{l}$ & $123(70-169)$ \\
Treatment & Radical operation & $14(50 \%)$ \\
Histological & G3 & $20(71.4 \%)$ \\
differentiation & & \\
\hline
\end{tabular}

Data are presented as median (range) or absolute frequency (\%). ALT, alanine aminotransferase; AST, aspartate aminotransferase; PHNET, primary hepatic neuroendocrine tumor; AFP, $\alpha$-fetoprotein; HB, hemoglobin; G3, tumor grade 3.

28 patients had received CT and MRI examinations, which had similar characteristics. We chosed a patient that had been performed CT scan in Fig. 2, which was representative. We had obtained patient consent for publication of the CT images shown in this manuscript and we had delieved all the imformations of the patient in Fig. 2.

Some researchers put forward that PHNETs diagnosis should focus on the comprehensive examination of NETs in the small intestine, colorectum, bronchus, lung, gall bladder, and pancreas, because the tiny lesions in these tissues may metastasize to the liver $(4,12-14)$. It is not easy to find tiny primary lesions during the process of diagnosis, but postoperative clinical follow-ups and auxiliary examinations are very helpful to detect these potential primary lesions.

In the past, PHNETs has been divided into two categories, carcinoid tumors and NECs. According to the diagnostic criteria of carcinoid tumors, the 28 cases of this study could not be classified as classical carcinoid tumors; therefore, we named them NETs. It is reported that there was no significant difference in the participation of men and women (15). In our study, slightly more men than women participated (1.15:1.0), mostly middle-aged and elderly people (average age $=53$ years) with single tumors (78.6\%), which was consistent with previous literature (4). Our results showed that the average survival time of the NET (G1, G2) group was 37.3 months and that of the NEC group was 14.9 months. The total survival rate of the NET $(\mathrm{G} 1, \mathrm{G} 2)$ group was significantly higher than that of the NEC group, indicating that using the WHO classification (2010) to classify PHNETs is reasonable and feasible (16). Some PHNETs are low-grade malignancies, which have a slow clinical progress, but some PHNETs have characteristics like invasive growth, relapse, and even distant metastasis. One case (NET G1, Ki-67 PI=3\%, single tumor, radical operation) with a 50-months follow-up showed no tumor recurrence until the end of the follow-up. One case (poorly differentiated, Ki-67 PI about 90\%, large patchy necrosis) in G3
Table II. Correlations of histological grade with clinicopathological characteristics.

\begin{tabular}{|c|c|c|c|}
\hline \multirow[b]{2}{*}{ Parameters } & \multicolumn{2}{|c|}{$\begin{array}{l}\text { Histological } \\
\text { grade }\end{array}$} & \multirow[b]{2}{*}{ P-value } \\
\hline & G1/G2 & G3 & \\
\hline Age, years & & & 0.629 \\
\hline$\leq 50$ & 4 & 8 & \\
\hline$>50$ & 4 & 12 & \\
\hline Sex & & & 0.811 \\
\hline Male & 4 & 11 & \\
\hline Female & 4 & 9 & \\
\hline $\mathrm{CA} 125, \mu \mathrm{g} / \mathrm{ml}$ & & & 0.220 \\
\hline$\leq 35$ & 8 & 15 & \\
\hline$>35$ & 0 & 3 & \\
\hline Unknown & 0 & 2 & \\
\hline Tumor size, cm & & & 0.793 \\
\hline$\leq 5$ & 3 & 7 & \\
\hline$>5$ & 3 & 9 & \\
\hline Unknown & 2 & 4 & \\
\hline $\mathrm{AFP}, \mu \mathrm{g} / 1$ & & & 0.497 \\
\hline$\leq 400$ & 8 & 17 & \\
\hline$>400$ & 0 & 1 & \\
\hline Unknown & 0 & 2 & \\
\hline Number of tumor lesions & & & 0.466 \\
\hline Single & 7 & 15 & \\
\hline Multiple & 1 & 5 & \\
\hline ALT, U/1 & & & $0.021^{\mathrm{a}}$ \\
\hline$\leq 40$ & 8 & 11 & \\
\hline$>40$ & 0 & 9 & \\
\hline AST, U/1 & & & $0.004^{\mathrm{b}}$ \\
\hline$\leq 40$ & 8 & 8 & \\
\hline$>40$ & 0 & 12 & \\
\hline $\mathrm{HB}, \mathrm{g} / \mathrm{l}$ & & & 0.159 \\
\hline$\leq 110$ & 1 & 8 & \\
\hline$>110$ & 7 & 12 & \\
\hline Treatment & & & 0.094 \\
\hline Radical operation & 2 & 12 & \\
\hline Others & 6 & 8 & \\
\hline Albumin, g/l & & & 0.053 \\
\hline$\leq 35$ & 0 & 7 & \\
\hline$>35$ & 8 & 13 & \\
\hline
\end{tabular}

${ }^{\mathrm{a}} \mathrm{P}<0.05$ and ${ }^{\mathrm{b}} \mathrm{P}<0.01$. AFP, $\alpha$-fetoprotein; ALT, alanine aminotransferase; AST, aspartate aminotransferase; CA125, carbohydrate antigen 125; HB, hemoglobin; G1-3, tumor grades 1-3.

died after a follow-up of two months. The pathological features of this patient indicated that the PHNETs was highly malignant, with rapid development and poor prognosis (15). These data showed that PHNETs is a heterogeneous tumor, and it is crucial to classify the PHNETs for guiding clinical prognosis and 

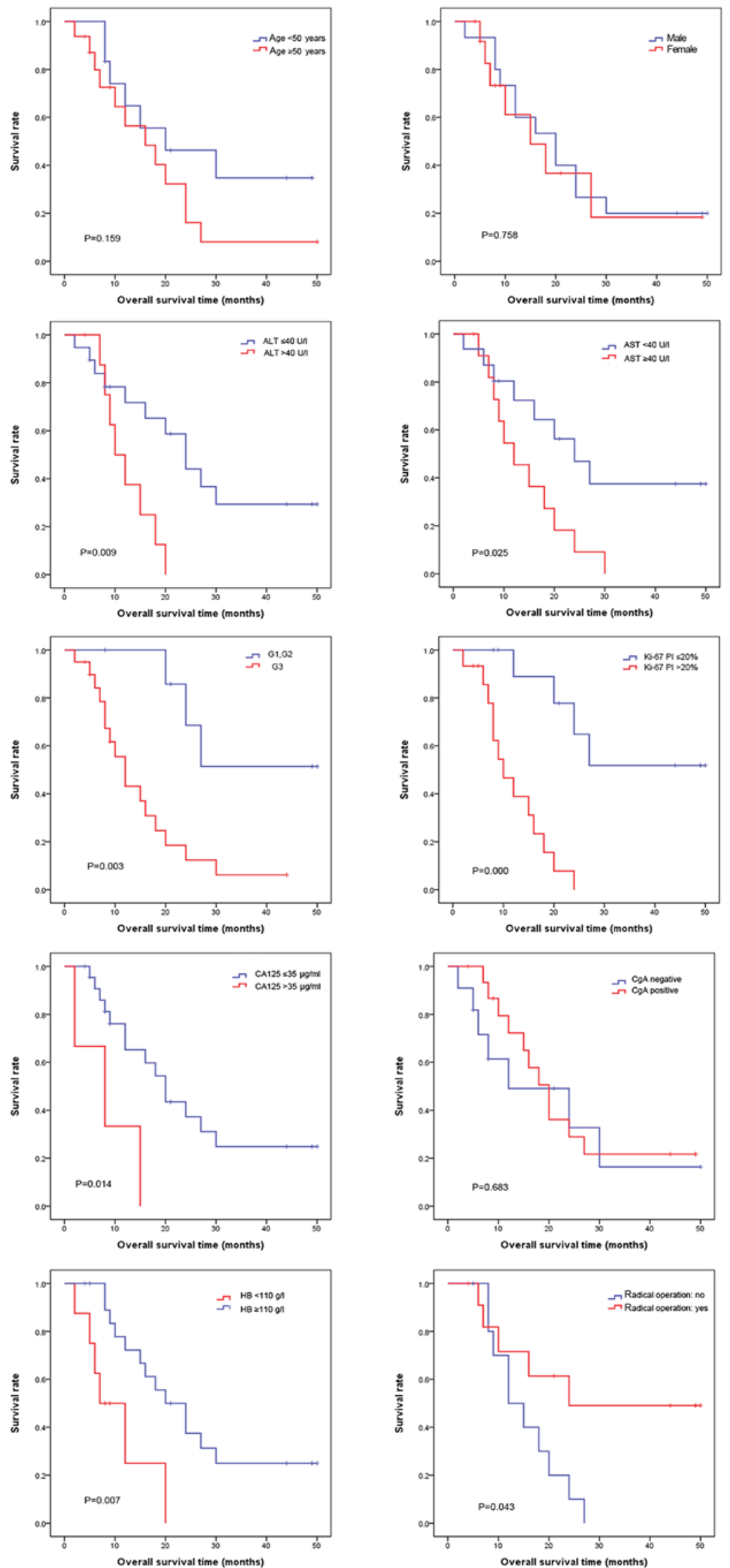

Figure 3. Patients were divided into low and high age groups, male and female groups, and CGA negative and positive groups; and the survival analysis was conducted respectively, showing no significant difference in overall survival rate $(\mathrm{P}>0.05)$. At the same time, the patients were divided into the ALT normal and abnormal groups, AST normal and abnormal groups, net (G1, G2) and NEC (G3) groups, Ki-67 PI >20\% and Ki-67 PI $\leq 20 \%$ groups, CA125 abnormal and normal groups, HB abnormal and normal groups, and the radical operation and others groups. Then the survival analysis was conducted respectively, revealing that the overall survival rate is significantly different $(\mathrm{P}<0.05)$. ALT, alanine aminotransferase; AST, aspartate aminotransferase; NEC, neuroendocrine carcinoma; G1-3, tumor grades 1-3; CA125, carbohydrate antigen 125; HB, hemoglobin; PI, Ki-67 positive index; CGA, chromogranin A. 
Table III. Cox proportional hazard regression analysis of patients' overall survival.

\begin{tabular}{|c|c|c|c|c|c|c|}
\hline \multirow[b]{2}{*}{ Variable } & \multicolumn{3}{|c|}{ Univariable } & \multicolumn{3}{|c|}{ Multivariable } \\
\hline & Hazard ratio & $95 \% \mathrm{CI}$ & P-value & Hazard ratio & $95 \% \mathrm{CI}$ & P-value \\
\hline Sex (male vs. female) & 1.156 & $0.451-2.967$ & 0.763 & - & - & - \\
\hline Age, years (>50 vs. $\leq 50)$ & 1.928 & $0.748-4.972$ & 0.174 & - & - & - \\
\hline ALT, U/l (>40 vs. $\leq 40)$ & 3.648 & $1.276-10.429$ & $0.016^{\mathrm{a}}$ & 1.021 & $0.291-47.353$ & 0.312 \\
\hline AST, U/l (>40 vs. $\leq 40)$ & 2.730 & $1.079-6.909$ & $0.034^{\mathrm{a}}$ & 3.564 & $0.006-1.110$ & 0.059 \\
\hline $\mathrm{HB}, \mathrm{g} / \mathrm{l}(>110$ vs. $\leq 110)$ & 0.256 & $0.088-0.745$ & $0.012^{\mathrm{a}}$ & 1.620 & $0.110-1.599$ & 0.203 \\
\hline Ki-67 PI (>20\% vs. $\leq 20 \%)$ & 8.980 & $2.439-33.064$ & $0.001^{\mathrm{b}}$ & 26.069 & $3.967-171.323$ & $0.001^{\mathrm{b}}$ \\
\hline CGA (positive vs. negative) & 0.824 & $0.319-2.132$ & 0.690 & - & - & - \\
\hline Tumor diameter, cm (>5 vs. $\leq 5)$ & 0.791 & $0.275-2.270$ & 0.662 & - & - & - \\
\hline Treatment (radical operation vs. others) & 0.269 & $0.093-0.779$ & $0.015^{\mathrm{a}}$ & 3.176 & $0.020-1.203$ & 0.075 \\
\hline $\mathrm{CA} 125, \mu \mathrm{g} / \mathrm{ml}(>35 \mathrm{vs} . \leq 35)$ & 4.639 & $1.191-18.064$ & $0.027^{\mathrm{a}}$ & 1.566 & $0.507-21.748$ & 0.212 \\
\hline
\end{tabular}

${ }^{\mathrm{a}} \mathrm{P}<0.05$ and ${ }^{\mathrm{b}} \mathrm{P}<0.001$. CI, confidence interval; ALT, alanine aminotransferase; AST, aspartate aminotransferase; HB, hemoglobin; Ki-67 PI, Ki-67 positive index; CGA, chromogranin A; CA125, carbohydrate antigen 125.

treatment according to its biological behaviors like slow growth, obvious malignancy, and even metastasis. In the G3 group, tumor tissues were mainly poorly differentiated, Ki-67 PI was high, and the necrosis was often combined. These pathological indicators may be correlated with the prognosis of PHNETs. At the same time, prognosis of patients with abnormal liver function indexes, such as ALT, was worse than for patients with normal liver function indexes, demonstrating that these clinical biochemical indexes may be correlated with the prognosis of PHNETs. In the NET group $(\mathrm{G} 1, \mathrm{G} 2)$, more cases showed high expression of $\mathrm{Ki}-67$ than in the NEC group, although still 3 cases had a lower expression of $\mathrm{Ki}-67$. This was similar to the ALT distribution, suggesting that this classification system can predict the severity of tumors to a certain extent, but has some limitations when the grading simply bases on ALT and Ki-67 PI, and the application of other pathological indexes for classification needs further investigation. The two groups did not exhibit any significant differences in tumor size, AFP, CEA, CGA, and albumin. Significant differences in these pathological indicators showed that it is reasonable and feasible to classify PHNETs into NET G1, NET G2, and NEC according to the WHO (2010) classification standard for neuroendocrine neoplasms of the digestive system. Furthermore, this classification can help to predict the severity and prognosis of PHNETs (17). However, although the WHO classification is for these cases identical, the prognosis still exhibits differences. Therefore, whether other pathological indicators have an effect on the prognosis and more accurate evaluation criteria are required needs to be further discussed. Regarding the effects of pathological indicators on the prognosis, the G1, G2 groups had a significantly higher survival rate than the $\mathrm{G} 3$ group, prompting that tumor grading has a guiding effect on prognosis. Grading can be used as an effective indicator of the prognosis for the cases where only a small quantity of tumor cells is available, e.g., for needle biopsy. The group of Ki-67 PI $\leq 20 \%$ had a higher total survival rate than the group of $\mathrm{Ki}-67$ PI $>20 \%(\mathrm{P}<0.05)$, suggesting that the expression level of Ki-67 has a guiding effect on the prognosis. The group of AST (ALT) $\leq 40 \mathrm{U} / 1$ had a higher total survival rate than the group of AST
$(\mathrm{ALT})>40 \mathrm{U} / 1(\mathrm{P}<0.05)$, suggesting that the levels of liver transaminases have a guiding effect on prognosis. The group of $\mathrm{HB}>110 \mathrm{G} / 1$ had a higher total survival rate than the group of $\mathrm{HB} \leq 110 \mathrm{G} / \mathrm{l}(\mathrm{P}<0.05)$, indicating that the anemia status has a guiding effect on prognosis. However, liver enzyme levels and low HB values may reflect not cause but result of the malignancy of the PHNETs in regards to the elevated liver enzyme levels and low HB values exhibited by malignant tumors. The group of $\mathrm{CA} 125 \leq 35 \mathrm{ug} / \mathrm{ml}$ had a higher total survival rate than the group of CA125 $>35 \mathrm{ug} / \mathrm{ml}(\mathrm{P}<0.05)$, indicating that an abnormal rise of CA125 has a guiding effect on prognosis. The operated group had a higher total survival rate than the non-operated group $(\mathrm{P}<0.05)$, suggesting that receiving a radical operation has a guiding effect on prognosis. The guiding effects of tumor size, AFP, CEA, CGA, and albumin on the prognosis were limited. It is revealed in this study that poor tumor grading, high expression of $\mathrm{Ki}-67$, poor liver function, and anemia are the main characteristics of malignant tumors: Tumor grading of G3, high expression of Ki-67, poor liver function, anemia, abnormal level of CA125, and lack of radical operation $(18,19)$ are correlated with shorter survival time and poor prognosis. Moreover, the high expression of $\mathrm{Ki}-67$ is an independent prognostic factor. All results support that these pathological indicators can help to predict the severity and prognosis of PHNETs.

\section{Acknowledgements}

The authors would like to thank Dr Qiu-Shuang Wang and Dr Xiao-meng Dai (Tongji Medical College) for their suggestions.

\section{Funding}

No funding was received.

\section{Availability of data and materials}

The datasets used and analyzed during the current study are available from the corresponding author on reasonable request. 


\section{Authors' contributions}

SY and JH conceived and designed the study. RC and MQ analyzed and interpreted the patient data. RC was a major contributor in writing the manuscript. $\mathrm{YC}, \mathrm{TZ}$ and $\mathrm{XH}$ contributed towards the acquisition of data, and data analysis and interpretation. YL, WS and TX helped with the acquisition of data. All authors read and approved the final manuscript.

\section{Ethics approval and consent to participate}

Ethical approval was requested and obtained from the Medical Ethics Committee of Tongji Medical College of Huazhong University of Science and Technology. Written informed consent was obtained from all participants.

\section{Consent for publication}

Written informed consent was obtained from all participants.

\section{Competing interests}

The authors declare that they have no competing interests.

\section{References}

1. Song JE, Kim BS and Lee CH: Primary hepatic neuroendocrine tumor: A case report and literature review. World J Clin Cases 4: 243-247, 2016.

2. Yang K, Cheng YS, Yang JJ, Jang X and Guo JX: Primary hepatic neuroendocrine tumor with multiple liver metastases: A case report with review of the literature. World J Gastroentero 21 : 3132-3138, 2015.

3. Camargo ÉS, Viveiros Mde M, Corrêa Neto IJ, Robles L and Rezende MB: Primary hepatic carcinoid tumor: Case report and literature review. Einstein (Sao Paulo) 12: 505-508, 2014 (In English, Portuguese)

4. Iwao M, Nakamuta M, Enjoji M, Kubo H, Fukutomi T, Tanabe Y, Nishi H, Taguchi KI, Kotoh K and Nawata H: Primary hepatic carcinoid tumor: Case report and review of 53 cases. Med Sci Monit 7: 746-750, 2001

5. Kellock T, Tuong B, Harris AC and Yoshida E: Diagnostic imaging of primary hepatic neuroendocrine tumors: A case and discussion of the literature. Case Rep Radiol 2014: 156491, 2014.

6. Li R, Tang CL, Yang D, Zhang XH, Cai P, Ma KS, Guo DY and Ding SY: Primary hepatic neuroendocrine tumors: Clinical characteristics and imaging features on contrast-enhanced ultrasound and computed tomography. Abdom Radiol (NY) 41: 1767-1775, 2016.
7. Morishita A, Yoneyama H, Nomura T, Sakamoto T, Fujita K, Tani J, Miyoshi H, Haba R and Masaki T: Primary hepatic neuroendocrine tumor: A case report. Mol Clin Oncol 4: 954-956, 2016.

8. Huang YQ, Xu F, Yang JM and Huang B: Primary hepatic neuroendocrine carcinoma: Clinical analysis of 11 cases. Hepatobiliary Pancreat Dis Int 9: 44-48, 2010.

9. Chen Z, Xiao HE, Ramchandra P and Huang HJ: Imaging and pathological features of primary hepatic neuroendocrine carcinoma: An analysis of nine cases and review of the literature. Oncol Lett 7: 956-962, 2014.

10. Pedrassa BC, da Rocha EL, Kierzenbaum ML, Bormann RL, Francisc VV and D'Ippolito G: Uncommon hepatic tumors: Iconographic essay-Parte 2. Radiol Bras 47: 374-379, 2014.

11. Yao JC, Hassan M, Phan A, Dagohoy C, Leary C, Mares JE, Abdalla EK, Fleming JB, Vauthey JN, Rashid A and Evans DB: One hundred years after 'carcinoid': Epidemiology of and prognostic factors for neuroendocrine tumors in 35,825 cases in the United States. J Clin Oncol 26: 3063-3072, 2008.

12. Yalav O, Ülkü A, Akçam TA, Demiryürek H and Doran F: Primary hepatic neuroendocrine tumor: Five cases with different preoperative diagnoses. Turk J Gastroenterol 23: 272-278, 2012.

13. Wang LX, Liu K, Lin GW and Jiang T: Primary hepatic neuroendocrine tumors: Comparing CT and MRI features with pathology. Cancer Imaging 15: 13, 2015.

14. Gravante G, De Liguori Carino N, Overton J, Manzia TM and Orlando G: Primary carcinoids of the liver: A review of symptoms, diagnosis and treatments. Dig Surg 25: 364-368, 2008.

15. Rocca A, Calise F, Marino G, Montagnani S, Cinelli M, Amato B and Guerra G: Primary giant hepatic neuroendocrine carcinoma: A case report. Int J Surg 1 (12 Suppl): S218-S221, 2014.

16. Cho CS, Labow DM, Tang L, Klimstra DS, Loeffler AG, Leverson GE, Fong Y, Jarnagin WR, D'Angelica MI, Weber SM, et al: Histologic grade is correlated with outcome after resection of hepatic neuroendocrine neoplasms. Cancer 113: 126-134, 2008.

17. Wang LM, An SL and Wu JX: Diagnosis and therapy of primary hepatic neuroendocrine carcinoma: Clinical analysis of 10 cases. Asian Pac J Cancer Prev 15: 2541-2546, 2014

18. Sutton R, Doran HE, Williams EMI, Vors J, Vinjamuri S, Evans J, Campbell F, Raraty MG, Ghaneh P, Hartley M, et al: Surgery for midgut carcinoid. Endocr Relat Cancer 10: 469-481, 2003.

19. Fenwick SW, Wyatt JI, Toogood GJ and Lodge JP: Hepatic resection and transplantation for primary carcinoid tumors of the liver. Ann Surg 239: 210-219, 2004. 